\title{
Identifikasi Determinasi Faktor Penentu Lokasi Pembangunan Permukiman Masyarakat Dan Perumahan Yang Dibangun Oleh Swasta Di Kabupaten Muna
}

\author{
Putri Herfa ${ }^{1)}$, Irfan $\mathrm{Ido}^{2)}$, Noor Husna Khairisa ${ }^{2)}$, \\ 1) Jurusan Geografi FITK Universitas Halu Oleo \\ 2) Jurusan Geografi FITK Universitas Halu Oleo \\ Email: putriherfa08@gmail.com
}

\begin{abstract}
Abstrak: Pertambahan penduduk di Kabupaten Muna menyebabkan peningkatan kebutuhan akan rumah. Penelitian ini bertujuan untuk: (1) mengidentifikasi faktor penentuan lokasi pembangunan permukiman masyarakat dan perumahan yang dibangun oleh swasta; (2) menganalisis perbedaan faktor dominan dalam penentuan lokasi pembangunan permukiman oleh masyarakat dan perumahan yang dibangun oleh swasta. Metode analisis data yang digunakan pada penelitian ini adalah analisis kuantitatif dan analisis kualitatif yang dilanjutkan dengan analisis faktor lokasi pembangunan permukiman dan pembangunan perumahan. Hasil penelitian ini antara lain: (1) Faktor penentu lokasi pembangunan permukiman oleh masyarakat dengan 3 urutan teratas antara lain: pelayanan air, listrik dan telepon, faktor kondisi jaringan lingkungan, dan keberadaan ruang terbuka. Faktor penentu lokasi pembangunan perumahan oleh swasta adalah faktor tingkat kemiringan lahan, faktor ketersediaan jaringan listrik, faktor kedekatan jarak, dan faktor kemudahan dalam pemasaran; (2) Faktor dominan dalam penentuan lokasi pembangunan permukiman oleh masyarakat antara lain tempat tinggal asal, ketersediaan lahan yang luas, harga tanah yang terjangkau, masuk dalam wilayah kota dan kondisi lingkungan. Sedangkan pengembang cenderung mempertimbangkan faktor letak, yaitu lokasi termasuk dalam daerah pengembangan kota, kedekatan jarak, lokasi yang strategis, harga tanah dan untuk memenuhi kebutuhan perumahan daerah.
\end{abstract}

\section{Kata kunci: Faktor penentu lokasi permukiman, faktor penentu lokasi perumahan}

Abstrak: Population growth in Muna Regency causes an increase in the need of house.This research aims to: (1) identify factors in determining the location of settlements development and housing development; (2) analyze the differences of dominant factors in determining the location of residential development by the community and housing builtby the private sector. Data in this research is analized by using quantitative and qualitative analysis followed by factor analysis of location of settlements development and housing development. The results of this study shows that: (1) The determining factors for the location of settlement development by the community with the top 3 ranking, namely, water, electricity and telephone services, environmental network conditions, and the existence of open spaces. The determining factors for the location of housing development by the private sector are the land slope, the availability of the electricity network, the proximity factor, and the convenience factor in marketing; (2) The dominant factors in determining the location of residential development by the communityi.e.the original place of resident, the available land is wide, affordable land prices, included in the city area and environmental conditions. Mean while, private sector tend to consider location factors, namely location is in urban development areas, proximity to distances, strategic locations, land price and to meet regional housing needs.

Keywords: Determining factors of settlement location, determining factors of housing location 


\section{PENDAHULUAN}

Rumah merupakan kebutuhan dasar manusia setelah sandang dan pangan yang berfungsi sebagai pelindung terhadap gangguan alam dan mahluk lainnya. Pembangunan perumahan permukiman merupakan bagian dari lingkungan hidup baik berupa kawasan perkotaan maupun pedesaan yang berfungsi sebagai lingkungan tempat tinggal yang terdiri dari beberapa tempat hunian. Pembangunan yang berkaitan dengan tempat tinggal dan lingkungannya perlu mendapatkan prioritas, mengingat tempat tinggal merupakan salah satu kebutuhan dasar manusia selain sandang dan pangan. (Santoso, 2011).

Berdasarkan UU No. 1 Tahun 2011 tentang Perumahan dan Kawasan Permukiman Pasal 1 ayat (2), perumahan adalah kumpulan rumah sebagai bagian dari permukiman, baik perkotaan maupun perdesaan, yang dilengkapi dengan prasarana, sarana, dan utilitas umum sebagai hasil upaya pemenuhan rumah yang layak huni.

Pemilihan lokasi untuk kawasan permukiman dan pembangunan perumahan mempunyai arti penting dalam aspek keruangan, karena hal ini akan menentukan keawetan bangunan, nilai ekonomi, dan dampak permukiman terhadap lingkungan disekitarnya. Dalam pemilihan lokasi perumahan ada banyak kriteria yang harus dipenuhi agar mendapatkan hasil yang optimal (Prawira, 2016).

Pembangunan perumahan bagi suatu lokasi permukiman dan perumahan yang dibangun oleh swasta perlu didasari dari berbagai bidang dengan pertimbangan persyaratan dasar fisik seperti topografi, sumber daya alam, lokasi tanah, letak geografis, iklim dan bencana alam. Selain itu dalam penentuan lokasi permukiman harus memperhatikan segi teknis pelaksanaan, tata guna lahan, kesehatan dan kemudahan serta politis (Prayogo, 1983 dalam Budiharjo,1984).

Meningkatnya jumlah penduduk Kabupaten Muna dari tahun 2010 sebanyak 197.497 jiwa hingga 2018 sebanyak 221.343 jiwa berdampak pada meningkatnya pula kebutuhan rumah hunian, hal tersebut terkendala dengan keterbatasan lahan yang berada di sekitar kota untuk dikembangkan sebagai lahan perumahan, sehingga lokasi pembangunan perumahan yang dibangun oleh pengembang perumahan (developer) di Kabupaten Muna mengarah ke 4 Kecamatan yaitu Kecamatan Lasalepa, Kecamatan Batalaiworu, Kecamatan Katobu, dan Kecamatan Duruka .

Pada lokasi pembangunan perumahan di empat Kecamatan Kabupaten Muna memiliki karakteristrik yang berbeda, mulai dari jenis tanah, kemiringan lereng, dan titik ketinggian. Penentuan lokasi pembangunan permukiman masyarakat dengan perumahan yang dibangun oleh pengembang perumahan (developer) di Kabupaten Muna, sebaiknya melihat keadaan faktor apa yang menjadi pertimbangan masyarakat dan pengembang perumahan (developer) dalam membangun perumahan di daerah tersebut.

Studi mengenai identifikasi determinasi faktor penentuan lokasi pembangunan permukiman masyarakat dengan perumahan yang dibangun oleh pengembang perumahan (developer) di Kabupaten Muna perlu dilakukan mengingat selama ini pembangunan perumahan banyak yang dilakukan tanpa terencana dengan baik terutama terkait masalah keruangan dan lingkungan. Oleh karena itu dalam menentukan lokasi pembangunan perumahan diperlukan suatu perencanaan yang matang dan pengelolaan yang baik agar dapat berkelanjutan tanpa merusak lingkungan. Begitu juga dengan penentuan lokasi perumahan di Kabupaten Muna diperlukan perencanaan yang 
komprehensif dengan mempertimbangkan faktor-faktor pemilihan lokasi pembangunan perumahan di daerah tersebut.

Berdasarkan yang telah dijelaskan, maka kita perlu mengidentifikasi faktor penentuan lokasi pembangunan permukiman masyarakat dengan perumahan yang dibangun oleh swasta pada kawasan perkotaan di Kabupaten Muna dan faktor dominan lokasi pembangunan perumahan.

Oleh karena itu, penelitian ini bertujuan untuk mengidentifikasi faktor penentuan lokasi pembangunan permukiman masyarakat dan perumahan yang dibangun oleh swasta serta menganalisis perbedaan faktor dominan dalam penentuan lokasi pembangunan permukiman oleh masyarakat dengan perumahan yang dibangun oleh swasta.

\section{METODE PENELITIAN}

\subsection{Lokasi Penelitian}

Penelitian ini dilaksanakan di Kecamatan Laselapa, Kecamatan Batalaiworu, Kecamatan Katobu, dan Kecamatan Duruka Kabupaten Muna. Berikut gambar lokasi penelitian.

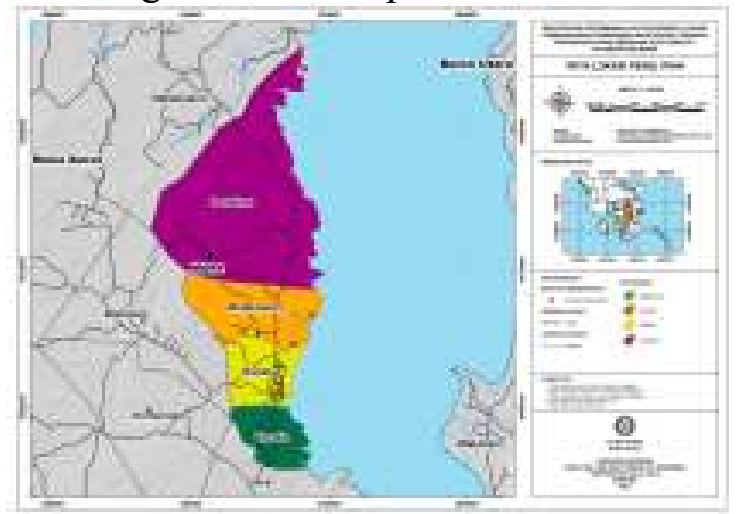

Gambar 1. Lokasi Peneletian

\subsection{Jenis Penelitian}

Penelitian ini menggunakan metode Mix Methods yang menggabungkan analisis kuantitatif dan analisis kualitatif. Analisis kuantitatif digunakan untuk menganalisis secara statistik hubungan antara variabel yang mempengaruhi pemilihan lokasi permukiman antar perumahan yang dibangun oleh swasta, sedangkan analisis kualitatif yang menggunakan pendekatan deskriptif.

\subsection{Teknik Pengumpulan Data}

Pengumpulan data dilakukan untuk memperoleh data sebagai bahan masukkan bagi tahapan analisis, bentuk tahapan ini berupa kegiatan pengambilan penyebaran kuesioner dan wawancara di empat Kecamatan di wilayah Kabupaten Muna. Jenis data penelitian yang akan digunakan pada penelitian ini yaitu data primer dan data sekunder.

\section{Data Primer}

Data primer adalah data yang diperoleh melalui pengumpulan data secara langsung dari objek penelitian melalui pengamatan langsung di lapangan (Sugiarto, 2001). Pengumpulan data primer dilakukan melalui kuesioner yang disebarkan kepada masyarakat di empat Kecamatan yang ada di wilayah Kabupaten Muna.

\section{Data Sekunder}

Data sekunder merupakan data-data yang telah disajikan secara tertulis, yang biasanya diproduksi oleh instansi pengeluar data yang berwenang. Data sekunder yang dibutuhkan dalam penelitian ini antar lain:

a. Peta Administrasi yang diperoleh dari PUPR Kabupaten Muna

\subsection{Sampel Penelitian}

Menurut Arikunto (2012) jika jumlah populasinya kurang dari 100 orang, maka jumlah sampelnya diambil secara keselurahan, tetapi jika populasinya lebih besar dari 100 orang, maka bisa diambil $10-15 \%$ atau $20-25 \%$ dari jumlah populasinya.

Berdasarkan penelitian ini karena jumlah populasinya ada yang lebih besar dan tidak lebih besar dari 100 orang responden, maka penulis menggunakan teknik pengambilan sampel purposive sampling dengan pertimbangan 30 orang kepala keluarga tersebut sudah dapat mewakili populasi dalam satu kecamatan secara proporsional. Jumlah responden yang 
didapat adalah berjumlah 30 kepala keluarga $\mathrm{x}$ empat kecamatan $=120$ responden. Responden pengembang (developer) jumlah populasinya tidak lebih

\subsection{Variabel Penelitian}

Menurut Sugiyono (2010), variabel penelitian adalah segala sesuatu yang berbentuk apa saja yang ditetapkan oleh peneliti untuk dipelajari sehingga diperoleh informasi tentang hal tersebut, kemudian ditarik kesimpulannya. Variabel yang digunakan dalam penelitian ini adalah variabel yang mempengaruhi pemilihan lokasi pembangunan permukiman masyarakat dan perumahan yang dibangun oleh swasta dapat dilihat pada Tabel 1 dan Tabel 2

Tabel 1 Variabel yang mempengaruhi masyarakat dalam memilih lokasi pembangunan permukiman dari 100 orang responden, maka pengambilan sampel menggunakan teknik sensus dengan 8 responden.

\begin{tabular}{|c|l|}
\hline No & \multicolumn{1}{|c|}{$\begin{array}{c}\text { Variabel yang Mempengaruhi } \\
\text { Masyarakat Dalam Memilih Lokasi } \\
\text { Pembangunan Permukiman }\end{array}$} \\
\hline 1 & $\begin{array}{l}\text { Pelayanan air, pelayanan listrik, dan } \\
\text { pelayanan telepon }\end{array}$ \\
\hline 2 & Kondisi drainase \\
\hline 3 & Kepadatan penduduk \\
\hline 4 & Bebas banjir \\
\hline 5 & Keberadaan kendaraan umum \\
\hline 6 & Keberadaan ruang terbuka \\
\hline 7 & Polusi \\
\hline 8 & Kondisi jalan lingkungan \\
\hline 9 & Kebersihan lingkungan \\
\hline 10 & Fasilitas Umum \\
\hline
\end{tabular}

Tabel 2 Variabel yang mempengaruhi pemilihan lokasi pembangunan perumahan oleh pengembang perumahan

\begin{tabular}{|c|l|}
\hline No & \multicolumn{1}{|c|}{$\begin{array}{c}\text { Variabel yang Mempengaruhi } \\
\text { Pemilihan Lokasi Pembangunan } \\
\text { Perumahan }\end{array}$} \\
\hline 1 & Fisik lahan \\
\hline 2 & $\begin{array}{l}\text { Adanya genangan yang terjadi pada } \\
\text { lahan yang akan dibangun perumahan }\end{array}$ \\
\hline 3 & Kedekatan jarak \\
\hline 4 & Ketersediaan \\
\hline 5 & Kepadatan penduduk \\
\hline
\end{tabular}

Vol.5 | No.2| 2021

\begin{tabular}{|c|l|}
\hline 6 & Harga lahan \\
\hline 7 & Pajak lahan \\
\hline 8 & Berada pada lahan perbatasan \\
\hline 9 & Tingkat kerawanan terhadap bencana \\
\hline 10 & Kemudahan pembebasan lahan \\
\hline 11 & Kemudahan dalam pemasaran \\
\hline 12 & $\begin{array}{l}\text { Keamanan dan kenyamanan } \\
\text { lingkungan }\end{array}$ \\
\hline
\end{tabular}

\subsection{Instrumen Penelitian}

Pada penelitian ini menggunakan daftar wawancara, untuk kegiatan wawancara yang langsung kepada masyarakat dengan pengembang perumahan tentang faktor apa yang menjadi dasar dalam penentuan lokasi pembangunan perumahan dan kueisoner terhadap masyarakat dengan pengembang perumahan.

Responden diminta untuk memberikan persetujuan pada skor nilai 1 sampai 5 yang tersedia. Angka 5 menunjukkan bahwa persepsi atau pendapat responden dengan skor paling tinggi dan angka 1 menunjukkan bahwa persepsi atau pendapat responden dengan skor paling rendah. Oleh karena itu, skala ini digunakan untuk mengukur pendapat dan persepsi responden terhadap faktor-faktor yang mempengaruhi masyarakat dan pengembang dalam pemilihan lokasi pembangunan perumahan di Kabupaten Muna.

\subsection{Teknik Analisis Data}

Pada intinya dengan teknik analisis ini bertujuan mentransformasikan data mentah ke dalam bentuk data yang mudah dimengerti oleh peneliti maupun orang lain (Singarimbum, 1989). Dalam faktor penentu lokasi pembangunan permukiman masyarakat dengan perumahan yang dibangun oleh swasta di Kabupaten Muna, maka metode analisis yang digunakan adalah metode gabungan kuantitatif dan kualititatif.

\section{Metode Analisis Kuantitatif}

Metode ini digunakan untuk menilai secara statistik terhadap hubungan antara variabel yang mempengaruhi pemilihan lokasi permukiman antar perumahan yang 
dibangun oleh swasta. Melihat data yang diperoleh, maka digunakan teknik "analisis faktor" untuk mencari faktor-faktor yang mempengaruhi pemilihan lokasi pembangunan permukiman masyarakat dengan perumahan yang dibangun oleh swasta berdasarkan persepsi masyarakat dan persepsi pengembang. Tujuan dari analisis ini adalah untuk meringkas informasi variabel dalam jumlah yang besar menjadi sejumlah faktor yang lebih kecil.

\section{a. Analisis Faktor}

Analisis faktor adalah teknik statistik yang digunakan untuk mengidentifikasi sejumlah faktor yang dapat mewakili hubungan antar jumlah variabel yang sangat berhubungan. Proses analisis faktor dilakukan dengan ekstrasi variabel hingga menjadi satu atau beberapa faktor dengan menggunakan SPSS. Pada penggunaan analisis faktor perlu dilakukan pengujian agar diketahui variabel yang layak untuk dilanjutkan ke dalam analisa faktor. Berikut adalah tahap pengujian data pada analisis faktor:

1. Uji independensi variabel dalam matriks korelasi

2. Rotasi Faktor

3. Penamaan Faktor

Tabel 3 Urutan kecenderungan faktor yang mempengaruhi masyarakat pemilihan lokasi permukiman

\begin{tabular}{clccc}
\hline Kode & \multicolumn{1}{c}{ Faktor } & Urutan & Mean & Standar Deviasi \\
\hline X1 & $\begin{array}{l}\text { Pelayanan air, listrik dan } \\
\text { telepon }\end{array}$ & 1 & 4,32 & 0,972 \\
\hline X2 & Kondisi drainase & 4 & 3,64 & 0,977 \\
\hline X3 & Kepadatan penduduk & 3 & 3,73 & 0,995 \\
\hline X4 & Bebas banjir & 2 & 4,10 & 1,111 \\
\hline X5 & $\begin{array}{l}\text { Keberadaan kendaraan } \\
\text { umum }\end{array}$ & 9 & $, 3,23$ & 1,075 \\
\hline X6 & Keberadaa ruang terbuka & 10 & 2,98 & 1,041 \\
\hline X7 & Polusi & 6 & 3,48 & 1,012 \\
\hline Kode & $\quad$ Faktor & Urutan & Mean & Standar Deviasi \\
\hline X8 & Kondisi jalan lingkungan & 7 & 3,37 & 0,909 \\
\hline X9 & Kebersihan lingkungan & 5 & 3,62 & 1,053 \\
\hline X10 & Fasilitas umum & 8 & 3,28 & \\
\hline Sumber: Hasil Analisis, 2021 & & & \\
\hline
\end{tabular}

\section{Metode Analisis Kualitatif}

Metode analisis kualitatif yang digunakan pada penelitian ini, menggunakan pendekatan deskriptif, pendekatan ini digunakan untuk menggambarkan kondisi secara sistematis, faktual dan akurat mengenai fakta-fakta, sifat-sifat, secara berhubungan antara faktor-faktor yang diselidiki (Nasir,1988).

\section{HASIL DAN PEMBAHASAN}

3.1 Faktor-faktor yang Mempengaruhi Masyarakat dalam Pemilihan Lokasi Permukiman

Pada analisis faktor yang mempengaruhi masyarakat dalam pemilihan lokasi permukiman, 10 data variabel awal yang digunakan sebagai data dasar dan diproses dengan menghilangkan satu persatu angka MSA (Measure of sampling adequacy). Urutan kecenderungan faktor yang mempengaruhi pemilihan lokasi permukiman berdasarkan hasil analisis deskriptif dapat dilihat pada Tabel 3 
Berdasarkan Tabel 3 menunjukkan persebaran jawaban responden pada faktor pengaruh pemilihan lokasi permukiman. Dimana apabila dalam Tabel 3, menunjukkan nilai rata-rata (mean) dari faktor lebih mendekati nilai 5 dan standar deviasinya lebih mendekati angka 1 maka dapat dikatakan faktor tersebut merupakan faktor yang lebih dominan terpilih dan sebagian besar responden sepakat terhadap jawaban tersebut.

Hasil analisa menunjukkan kecenderungan masyarakat dalam mempertimbangkan faktor pemilihan lokasi permukiman. Berdasarkan hasil analisa deskriptif, variabel/faktor yang paling dominan terpilih oleh responden adalah Pelayanan air, listrik, dan telepon.

\section{Analisa Faktor Pemilihan Lokasi Permukiman}

Menurut Santoso (2010), analisa faktor ini memiliki tujuan untuk mengidentifikasi adanya hubungan faktor satu dengan faktor lainnya dengan menguji korelasi antar faktor tersebut, kemudian menjadi bentuk pengelompokan data yang membuat kelompok-kelompok baru untuk menggantikan sejumlah faktor tertentu.

Tahap pertama, sebelum menganalisa lebih lanjut pada analisis faktor yang dilakukan adalah dengan menguji asumsi pada analisis faktor. Pengujian tersebut dilakukan kepada sepuluh faktor yang ada dalam penelitian dan dapat dilihat pada Tabel 4

Tabel 4 Uji analisis faktor

\begin{tabular}{|c|c|c|}
\hline Asumsi Analisis Faktor & Hasil Data Analisa & Kesimpulan \\
\hline $\begin{array}{l}\text { Data yang terambil telah mencukupi } \\
\text { dan dapat difaktorkan apabila Nilai } \\
\text { KMO harus lebih besar dari } 0,50 \text {. }\end{array}$ & Nilai KMO : 0,698 & 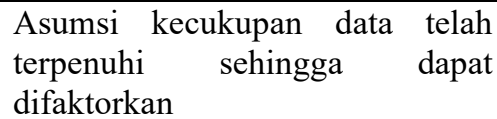 \\
\hline $\begin{array}{l}\text { Antar variabel berkorelasi apabila nilai } \\
\text { signifikansi dari Bartlett's Testof } \\
\text { Sphericity kurang dari a } 1,00\end{array}$ & Nilai signifikansi :0,000 & $\begin{array}{l}\text { Faktor untuk pemilihan lokasi } \\
\text { permukiman memenuhi asumsi } \\
\text { saling berkorelasi }\end{array}$ \\
\hline $\begin{array}{l}\text { Analisis faktor memang tepat untuk } \\
\text { menganalisa data dalam bentuk matriks } \\
\text { korelasi apabila nilai Measures of } \\
\text { Sampling Adequacy (MSA) masing- } \\
\text { masing variabel memiliki nilai lebih } \\
\text { dari } 0,50\end{array}$ & $\begin{array}{lrr}\text { Terdapat } & 10 & \text { (sepulu) } \\
\text { variabel yang } & \text { memiliki } \\
\text { nilai } & & \\
\text { MSA* } & \text { kurang } & \text { lebih dari } \\
0,50 & & \end{array}$ & $\begin{array}{l}\text { Sehingga terdapat } 10 \text { (sepuluh) } \\
\text { faktor yang dapat memenuhi } \\
\text { asumsi bahwa analisa faktor } \\
\text { memang tepat untuk menganalisa } \\
\text { data dalam bentuk matriks } \\
\text { korelasi. }\end{array}$ \\
\hline
\end{tabular}

Tahapan Uji Asumsi Analisis Faktor

Berdasarkan hasil pengujian asumsi yang tercantum pada Tabel 4 faktor yang memenuhi asumsi bahwa analisa faktor memang tepat untuk menganalisa data dalam bentuk matriks korelasi. Maka selanjutnya adalah pengukuran yang menentukan jumlah kelompok faktor pemilihan lokasi permukiman. Berdasarkan variansi faktor yang terbentuk hanya terdapat 3 (tiga) faktor yang terbentuk, dimulai dari urutan terbesar yakni :

1. Faktor 1 (compenent 1) dengan nilai eigenvalues sebesar 3,073 dan memiliki variansi yang bisa dijelaskan sebesar 30,730\% (3,073 / 10 faktor $\mathrm{x}$ $100 \%=30,730 \%)$;

2. Faktor 2 (compenent 2) dengan nilai eigenvalues sebesar 1,596 dan memiliki variansi yang bisa dijelaskan sebesar 15,959\% (1,596 / 10 faktor $\mathrm{x}$ $100 \%=15,969 \%)$;

3. Faktor 3 (compenent 3) dengan nilai eigenvalues sebesar 1,250 dan memiliki variansi yang bisa dijelaskan sebesar $12,499 \%(1,250 / 10$ faktor $\mathrm{x}$ $100 \%=12,50 \%)$.

Hasil analisa rotasi maka diketahui pula besaran distribusi (loading factor) kesepuluh faktor terhadap ketiga faktor baru yang terbentuk dalam Tabel 5 
Tabel 5 Faktor terhadap faktor baru yang terbentuk

\begin{tabular}{|c|c|l|c|c|c|}
\hline Kelompok Faktor & Kode & \multicolumn{1}{|c|}{ Faktor } & \multicolumn{3}{|c|}{ Loading Factor pada Kelompok } \\
\cline { 4 - 6 } & & & Faktor Baru* \\
\cline { 3 - 6 } & & & FB 1 & FB 2 & FB 3 \\
\hline \multirow{4}{*}{1} & $\mathrm{X} 1$ & Pelayanan air, listrik dan telepon & 0,775 & 0,138 & $-0,213$ \\
\cline { 2 - 6 } & $\mathrm{X} 2$ & Kondisi drainase & 0,548 & 0,526 & $-0,60$ \\
\cline { 2 - 6 } & $\mathrm{X} 3$ & Kepadatan penduduk & 0,645 & $-0,119$ & 0,237 \\
\cline { 2 - 6 } & $\mathrm{X} 4$ & Bebas banjir & 0,642 & 0,268 & $-0,027$ \\
\cline { 2 - 6 } & $\mathrm{X} 5$ & Keberadaan kendaraan umum & 0,779 & 0,023 & 0,278 \\
\hline \multirow{3}{*}{2} & $\mathrm{X} 8$ & Kondisi jalan lingkungan & 0,162 & 0,743 & 0,109 \\
\cline { 2 - 6 } & $\mathrm{X} 9$ & Kondisi lingkungan & $-0,070$ & 0,753 & 0,114 \\
\cline { 2 - 6 } & $\mathrm{X} 10$ & Fasilitas umum & 0,109 & 0,660 & 0,129 \\
\hline \multirow{3}{*}{3} & $\mathrm{X} 6$ & Keberadaan ruang terbuka & 0,216 & 0,204 & 0,765 \\
\cline { 2 - 6 } & $\mathrm{X} 7$ & Polusi & $-0,071$ & 0,114 & 0,828 \\
\hline
\end{tabular}

Sumber: Hasil Analisis, 2021.

Tabel 5 menunjukkan bahwa faktor loading pada component matriks maka didapatkan analisa diatas yang mempengaruhi dalam pemilihan lokasi permukiman dapat dilihat pada Tabel 6 .

Tabel 6 Faktor yang memengaruhi pemilihan lokasi perumahan berdasarkan persepsi masyarakat

\begin{tabular}{|c|l|l|}
\hline No & \multicolumn{1}{|c|}{ Faktor } & \multicolumn{1}{|c|}{ Variabel } \\
\hline 1 & \multirow{2}{*}{ Faktor Baru 1 } & $\begin{array}{l}\text { Pelayanan air, listrik, dan } \\
\text { telepon }\end{array}$ \\
\cline { 3 - 3 } & & Kondisi drainase \\
\cline { 3 - 3 } & & Kepadatan penduduk \\
\cline { 3 - 3 } & & Bebas banjir \\
\cline { 3 - 3 } & \multirow{2}{*}{ Faktor Baru 2 } & Kendaraan umum \\
\cline { 3 - 3 } & & Kendisi jalan lingkungan \\
\cline { 3 - 3 } & & Fasilitas umum \\
\hline 3 & Faktor Baru 3 & $\begin{array}{l}\text { Keberadaan } \\
\text { terbuka }\end{array}$ \\
\cline { 3 - 3 } & & Polusi \\
\hline
\end{tabular}

(Sumber: Hasil Analisis, 2021)

\subsection{Faktor-faktor yang Mempengaruhi Pengembang dalam Pemilihan Lokasi Pembangunan Perumahan \\ 1. Faktor Pemilihan Lokasi Pembangunan Perumahan}

Pada analisis faktor yang mempengaruhi pengembang perumahan dalam memilih lokasi pembangunan perumahan, 12 data variabel awal yang digunakan sebagai data dasar dan diproses dengan menghilangkan satu persatu angka MSA. Urutan kecenderungan faktor yang mempengaruhi pemilihan loasi pembangunan perumaha berdasarkan hasil analisis deskriptif dapat dilihat pada Tabel 7.

Tabel 7 Urutan kecenderungan faktor yang mempengaruhi pemilihan lokasi pembangunan perumahan berdasarkan hasil analisis deskriptif

\begin{tabular}{|c|l|c|c|c|}
\hline Kode & \multicolumn{1}{|c|}{ Faktor } & Urutan & Mean & Standar Deviasi \\
\hline X1 & Tingkat kemiringan lahan yang akan dibangun perumahan & 1 & 4,88 & 0,354 \\
\hline X3 & $\begin{array}{l}\text { Adanya genangan yang terjadi pada lahan yang akan } \\
\text { dibangun perumahan }\end{array}$ & $\begin{array}{l}\text { Kedekatan jarak antara lokasi perumahan dengan Pasar, } \\
\text { Warung/Kios, Toko, Perkantoran, Area wisata, } \\
\text { Permukiman, dan Fasilitas Kesehatan }\end{array}$ & 6,00 & 0,926 \\
\hline X4 & $\begin{array}{l}\text { Ketersediaan Jaringan listrik beserta pelayanannya dan } \\
\text { Sumber daya air beserta jaringannya }\end{array}$ & 2 & 4,88 & 0,318 \\
\hline Kode & $\begin{array}{l}\text { Tingkat kepadatan penduduk sekita lahan lokasi } \\
\text { pembangunan perumahan }\end{array}$ & 9 & 4,13 & 0,835 \\
\hline X5 Xrutan & Mean & Standar Deviasi \\
\hline X6 & \begin{tabular}{l} 
Tingkat harga lahan \\
\hline
\end{tabular} \\
\hline
\end{tabular}




\begin{tabular}{|c|l|c|c|c|}
\hline X7 & Besarnya pajak lahan yang akan dibangun perumahan & 11 & 4,00 & 0,926 \\
\hline X8 & $\begin{array}{l}\text { Berada pada lahan perbatasan atau lahan kota yang } \\
\text { lingkungannya sedang berkembang }\end{array}$ & 12 & 3,75 & 1,165 \\
\hline X9 & Tingkat kerawanan terhadap bencana & 3 & 4,88 & 0,354 \\
\hline X10 & Kemudahan pembebasan lahan & 4 & 4,75 & 0,463 \\
\hline X11 & Kemudahan dalam pemasaran & 11 & 4,25 & 1,035 \\
\hline X12 & Keamanan dan kenyamanan lingkungan & 5 & 4,63 & 0,518 \\
\hline
\end{tabular}

Sumber: Hasil Analisis, 2021

Tabel 7 menunjukkan persebaran jawaban responden pada faktor pengaruh pemilihan lokasi pembangunan perumahan. Dimana apabila dalam Tabel 7, menunjukkan nilai rata-rata (mean) dari faktor lebih mendekati nilai 5 dan standar deviasinya lebih mendekati angka 1 maka dapat dikatakan faktor tersebut merupakan faktor yang lebih dominan terpilih dan sebagian besar responden sepakat terhadap jawaban tersebut.

Hasil analisa menunjukkan kecenderungan developer dalam mempertimbangkan faktor pemilihan lokasi pembangunan perumahan. Berdasarkan hasil analisa deskriptif, variabel/faktor yang paling dominan terpilih oleh responden adalah tingkat kemirirngan lahan yang akan dibanguna perumahan.

\section{Analisa Faktor Pemilihan Lokasi Pembangunan Perumahan}

Hasil dari analisis faktor adalah kelompok faktor baru yang mengindikasikan faktor yang menjadi pertimbangan pada saat pengembang memilih lokasi untuk pembangunan perumahan. Selanjutnya adalah pengukuran yang menentukan jumlah kelompok faktor pemilihan lokasi pembangunan perumahan.

Terdapat 4 (empat) faktor yang terbentuk, dimulai dari urutan terbesar yakni :

1. Faktor 1 (compenent 1) dengan nilai eigenvalues sebesar 3,535 dan memiliki variansi yang bisa dijelaskan sebesar 29,460\% (3,535 / 12 faktor $\mathrm{x}$ $100 \%=29,458 \%)$;

2. Faktor 2 (compenent 2) dengan nilai eigenvalues sebesar 3,428 dan memiliki variansi yang bisa dijelaskan sebesar 28,567\% (3,428 / 12 faktor $\mathrm{x}$ $100 \%=28,567 \%)$;

3. Faktor 3 (compenent 3) dengan nilai eigenvalues sebesar 2,200 dan memiliki variansi yang bisa dijelaskan sebesar 18,337\% (2,200 / 12 faktor $\mathrm{x}$ $100 \%=18,33 \%)$.

4. Faktor 4 (compenent 4) dengan nilai eigenvalues sebesar 1,343 dan memiliki variansi yang bisa dijelaskan sebesar $11,189 \%(1,343 / 12$ faktor $\mathrm{x}$ $100 \%=11,192 \%)$.

Hasil analisa rotasi, maka diketahui pula besaran distribusi (loading factor) kedua belas faktor terhadap keempat faktor baru yang terbentuk yang disajikan dalam Tabel 8.

Tabel 8 Faktor terhadap faktor baru yang terbentuk

\begin{tabular}{|c|c|l|c|c|c|c|}
\hline \multirow{2}{*}{$\begin{array}{l}\text { Kelompok } \\
\text { Faktor }\end{array}$} & Kode & \multicolumn{1}{|c|}{ Faktor } & \multicolumn{3}{|c|}{ Loading Factor pada Kelompok Faktor } \\
\cline { 3 - 7 } & $\mathrm{X} 1$ & $\begin{array}{l}\text { Tingkat kemiringan lahan yang akan } \\
\text { dibangun perumahan }\end{array}$ & 0,191 & $-0,256$ & $-0,374$ & $-0,814$ \\
& $\mathrm{X} 2$ & $\begin{array}{l}\text { Adanya genangan yang terjadi pada } \\
\text { lahan yang akan dibangun perumahan }\end{array}$ & 0,885 & 0,233 & $-0,029$ & $-0,394$ \\
\cline { 2 - 7 } & $\mathrm{X}$ & Tingkat harga lahan & 0,820 & $-0,019$ & 0,070 & 0,521 \\
\hline
\end{tabular}




\begin{tabular}{|c|c|c|c|c|c|c|}
\hline & & & & & \multicolumn{2}{|c|}{ | Vol.5 | No.2| 2021} \\
\hline & $\mathrm{X} 7$ & $\begin{array}{l}\text { Besarnya pajak lahan yang akan } \\
\text { dibangun perumahan }\end{array}$ & 0,944 & 0,243 & $-0,057$ & 0,151 \\
\hline & $\mathrm{X} 12$ & $\begin{array}{lll}\begin{array}{l}\text { Keamanan } \\
\text { lingkungan }\end{array} & \text { dan } & \text { kenyamanan } \\
\end{array}$ & 0,769 & $-0,459$ & $-0,363$ & $-0,031$ \\
\hline 2 & $\mathrm{X} 4$ & $\begin{array}{l}\text { Ketersediaan Jaringan listrik beserta } \\
\text { pelayanannya dan Sumber daya air } \\
\text { beserta jaringannya }\end{array}$ & 0,225 & 0,939 & 0,050 & $-0,97$ \\
\hline & X9 & Tingkat kerawanan terhadap bencana & 0,225 & 0,939 & 0,050 & $-0,097$ \\
\hline & $\mathrm{X} 10$ & Kemudahan pembebasan lahan & $-0,194$ & 0,833 & 0,038 & 0,100 \\
\hline 3 & $\mathrm{X} 3$ & $\begin{array}{l}\text { Kedekatan jarak antara lokasi } \\
\text { perumahan dengan } \\
\text { Warung/Kios, Toko, Perkantoran, } \\
\text { Area wisata, Permukiman, dan } \\
\text { Fasilitas Kesehatan }\end{array}$ & $-0,029$ & 0,343 & 0,896 & 0,112 \\
\hline & $\mathrm{X} 5$ & $\begin{array}{l}\text { Tingkat kepadatan penduduk sekita } \\
\text { lahan lokasi pembangunan perumahan }\end{array}$ & 0,088 & 0,030 & 0,904 & 0,140 \\
\hline & $\mathrm{X} 8$ & $\begin{array}{l}\text { Berada pada lahan perbatasan atau } \\
\text { lahan kota yang lingkungannya sedang } \\
\text { berkembang }\end{array}$ & $-0,261$ & $-0,182$ & 0,651 & $-0,133$ \\
\hline 4 & $\mathrm{X} 11$ & Kemudahan dalam pemasaran & $0,274-$ & 0,459 & $-0,363$ & $-0,031$ \\
\hline
\end{tabular}

Sumber: Hasil Analisis, 2021.

Berdasarkan faktor loading pada component matriks maka didapatkan analisa yang mempengaruhi dalam pemilihan lokasi perumahan (Tabel 9).

Tabel 9 Faktor yang memengaruhi pemilihan lokasi perumahan berdasarkan persepsi developer

\begin{tabular}{|c|c|c|}
\hline No & Faktor & Variabel \\
\hline \multirow[t]{5}{*}{1} & \multirow[t]{5}{*}{$\begin{array}{l}\text { Kelompok } \\
\text { Faktor } 1\end{array}$} & $\begin{array}{l}\text { Tingkat kemiringan lahan } \\
\text { yang akan dibangun } \\
\text { perumahan }\end{array}$ \\
\hline & & $\begin{array}{l}\text { Adanya genangan yang } \\
\text { terjadi pada lahan yang } \\
\text { akan } \\
\text { perumahan }\end{array}$ \\
\hline & & Tingkat harga lahan \\
\hline & & $\begin{array}{l}\text { Besarnya pajak lahan } \\
\text { yang akan dibangun } \\
\text { perumahan }\end{array}$ \\
\hline & & $\begin{array}{l}\text { Keamanan dan } \\
\text { kenyamanan lingkungan }\end{array}$ \\
\hline \multirow[t]{3}{*}{2} & \multirow[t]{3}{*}{$\begin{array}{l}\text { Kelompok } \\
\text { Faktor } 2\end{array}$} & $\begin{array}{lr}\text { Ketersediaan } & \text { Jaringan } \\
\text { listrik } & \text { beserta } \\
\text { pelayanannya } & \text { dan } \\
\text { Sumber daya } & \text { air } \\
\text { jaringannya } & \\
\end{array}$ \\
\hline & & $\begin{array}{l}\text { Tingkat kerawanan } \\
\text { terhadap bencana }\end{array}$ \\
\hline & & $\begin{array}{l}\text { Kemudahan pembebasan } \\
\text { lahan }\end{array}$ \\
\hline No & Faktor & Variabel \\
\hline 3 & $\begin{array}{l}\text { Kelompok } \\
\text { Faktor } 3\end{array}$ & $\begin{array}{l}\text { Kedekatan jarak antara } \\
\text { lokasi perumahan dengan }\end{array}$ \\
\hline
\end{tabular}

\begin{tabular}{|c|c|c|}
\hline & & $\begin{array}{l}\text { Pasar, Warung/Kios, } \\
\text { Toko, Perkantoran, Area } \\
\text { wisata, Permukiman, dan } \\
\text { Fasilitas Kesehatan }\end{array}$ \\
\hline & & $\begin{array}{lr}\text { Tingkat } & \text { kepadatan } \\
\text { penduduk } & \text { sekita lahan } \\
\text { lokasi } & \text { pembangunan } \\
\text { perumahan } & \end{array}$ \\
\hline & & $\begin{array}{l}\text { Berada pada lahan } \\
\text { perbatasan atau lahan } \\
\text { kota yang lingkungannya } \\
\text { sedang berkembang }\end{array}$ \\
\hline 4 & $\begin{array}{l}\text { Kelompok } \\
\text { Faktor } 4\end{array}$ & $\begin{array}{l}\text { Kemudahan } \\
\text { pemasaran }\end{array}$ \\
\hline
\end{tabular}

(Sumber: Hasil Analisis, 2021)

\subsection{Hasil Wawancara Faktor Dominan Masyarakat Dalam Memilih Lokasi Permukiman}

Berdasarkan hasil survey dan wawancara kepada masyarakat faktor dominan dalam memilih lokasi permukiman di empat Kecamatan yaitu Kecamatan Lasalepa, Kecamatan Batalaiworu, Kecamatan Katobu dan Kecamatan Duruka terkait tentang alasan memilih lokasi permukiman adalah karna faktor tanah, didapatkan data seperti yang terdapat pada Gambar 2. 


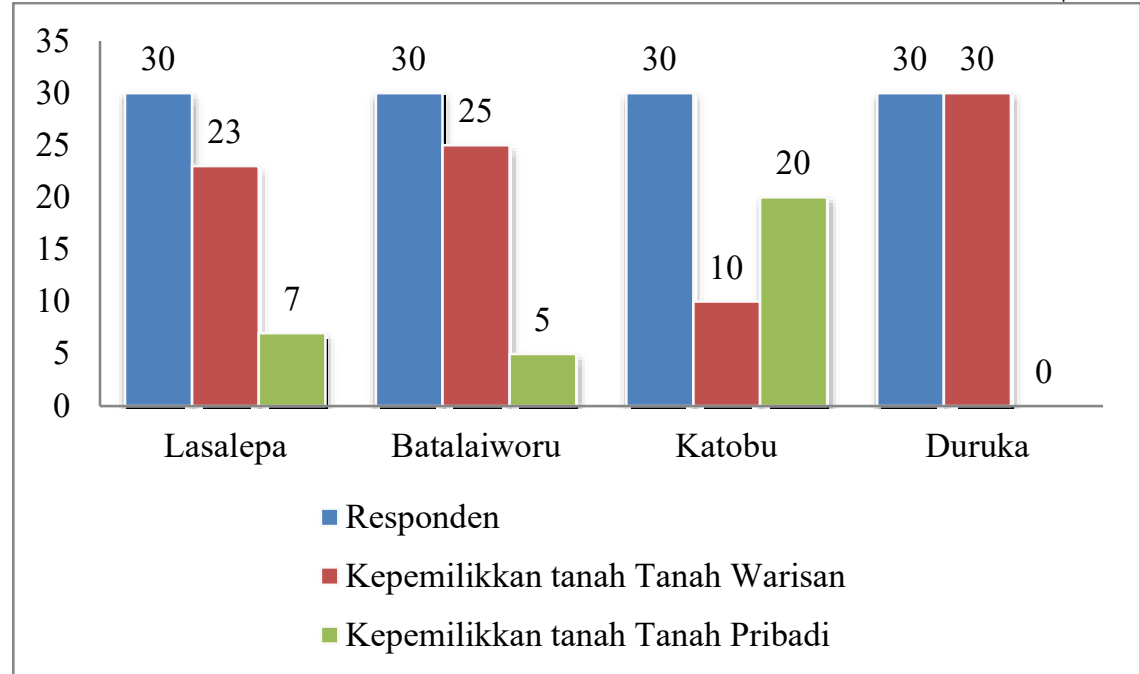

Gambar 2. Diagram Kepemilikan Tanah

\subsection{Hasil Wawancara Developer Dalam Memilih Lokasi Pembangunan Perumahan}

Alasan developer (pengembang perumahan) memilih lokasi pembangunan perumahan di Kecamatan Lasalepa yaitu karena Kecamatan Lasalepa akan menjadi pusat pemerintahan perkotaan di Kabupaten Muna. Alasan di Kecamatan Batalaiworu karena berada pada lahan perbatasan atau lahan kota yang lingkungannya sedang berkembang. Faktor yang dipertimbangkan pengembang perumahan di Kecamatan Katobu karena Kecamatan Katobu merupakan pusat kegiatan masyarakat di Kabupaten Muna. Sedangkan alasan di Kecamatan Duruka yaitu karena kepemilikkan tanah yang ada di Kecamatan Duruka adalah milik pemerintah, sehingga pemerintah memanfaatkan tanah tersebut untuk membangun perumahan.

\subsection{Faktor Dominan Developer Dalam Memilih Lokasi Pembangunan Perumahan}

Faktor dominan penentu lokasi pembangunan perumahan oleh developer (pengembang perumahan) yaitu faktor kedekatan jarak antara perkantoran, sekolah, pusat kesehatan, wisata, pasar, toko, kios, faktor menjadi penentu dalam penentuan lokasi pembangunan perumahan oleh pengembang perumahan di $\begin{array}{lrr}\text { Kecamatan } \quad \text { Lasalepa, } & \text { Kecamatan } \\ \text { Batalaiworu, Kecamatan } & \text { Katobu, } \\ \text { Kecamatan Duruka. } & \end{array}$

\section{KESIMPULAN}

Berdasarkan penelitian ini antara lain:

1. Faktor penentu lokasi pembangunan permukiman oleh masyarakat dengan 3 urutan teratas antara lain: pelayanan air, listrik dan telepon, faktor kondisi jaringan lingkungan, dan keberadaan ruang terbuka. Faktor penentu lokasi pembangunan perumahan oleh swasta adalah faktor tingkat kemiringan lahan, faktor ketersediaan jaringan listrik, faktor kedekatan jarak, dan faktor kemudahan dalam pemasaran

2. Faktor dominan dalam penentuan lokasi pembangunan permukiman oleh masyarakat antara lain tempat tinggal asal, ketersediaan lahan yang luas, harga tanah yang terjangkau, masuk dalam wilayah kota dan kondisi lingkungan. Sedangkan pengembang cenderung mempertimbangkan faktor letak, yaitu lokasi termasuk dalam daerah pengembangan kota, kedekatan jarak, lokasi yang strategis, harga tanah dan untuk memenuhi kebutuhan perumahan daerah.

\section{DAFTAR PUSTAKA}

Arikunto, Suharsimi. (2012). Prosedur Penelitian.Jakarta:n Rineka Cipta. 
Budihardjo, Eko, (1997), Arsitektur dan Kota di Indonesia, PT. Alumni, Bandung.

Nasir, Moh, Metode Penelitian, Ghalia Indonesia, Jakarta, 1988.

Prawira. D. D. S., Rini. R., Wulan. E. T., Mei, (2016). Penentuan Prioritas Lokasi Perumahan Di Kecamatan Kasihan Dengan Menggunakan Sistem Informasi Geografis. Jurnal Geodesi Undip. 3 (4), 237-845.

Santoso, A. (2011). Serat Pangan (Dietary Fiber) Dan Manfaatnya Bagi Kesehatan. Jurusan Teknologi Hasil
Pertanian, Fakultas Teknologi Pertanian, Unwidha Klaten.

Singarimbun, Masri dan Efendi, Sofian, Metode Penelitian Survey, LP3ES, Jakarta, (1989)

Sugiarto, D. Siagian, Lesmono Tri Sunaryanto, Deni S. Oetomo, Teknik Sampling, Gramedia Jakarta, (2001).

Sugiyono, (2010), Metode Penelitian Kuantitatif dan Kualitatif dan $R \& D$, Penerbit Alfabeta, Bandung.

Undang-Undang Nomor 1 Tahun (2011) tentang Perumahan dan Kawasan Permukiman. 